\title{
Effect of Masonry Infill Structure with Openings during Progressive Collapse by Removing a Middle Column
}

\author{
M. Sakthi Seethalakshmi* , M. Prakash, K. S. Satyanarayanan and V. Thamilarasu \\ Department of Civil Engineering, SRM University, Chennai - 603203, Tamil Nadu, India; \\ msaks16@gmail.com, prakash.m@ktr.srmuniv.ac.in, sathyanarayanan@ktr.srmuniv.ac.in, \\ thamilarasu.v@ktr.srmuniv.ac.in
}

\begin{abstract}
Background/Objectives: Progressive collapse occurs when primary structural element fails due to many reasons such as impact, bomb blast, earthquake, abnormal loading etc., resulting in the failure of adjoining structural elements, which in turn causes partial or total collapse of the structure consequently. It is studied widely in Reinforced Concrete (RC) framed structure. Methods/Statistical Analysis: The present study investigates the comparative behaviour of four bay, five storey $\mathrm{RC}$ bare frame, infilled frame and infilled frame with openings and to assess the effect of infill to resist the progressive collapse. A linear static analysis is carried out using finite element software using SAP 2000 and maximum moment (M), shear force $(\mathrm{V})$, axial force $(\mathrm{P})$, deflection $(\mathrm{U})$ for both beams and columns generated before and after middle column removal are studied and compared. Findings: There is an average of $30 \%$ and $34 \%$ decrease in moments for infilled frames when compared to a bare frame. The percentage of decrease in moments increases to an average of $71 \%$ when the column is removed. Similarly, the deflection for infilled frames decreases by $35 \%$ when compared with bare frame and only $17 \%$ increase when infills are provided with openings on removal of column there is average of $88 \%$ decrease in deflection for infilled frames when compared with bare frame. It shows that the presence of infilled frames will delay the progressive collapse when compared to bare frames. Application/Improvements: The study can be extended to the non-linear range and also to find its dynamic response.
\end{abstract}

Keywords: Infilled Frame and Infilled Frame with Openings, Progressive Collapse, RCC Frame

\section{Introduction}

Research in Progressive collapse has gained momentum in 2000. Due to the increase in trigger mechanism such as impact, bomb blast, earthquake etc. loss of critical elements leads to increase in moments and stresses which progresses to nearby elements ultimately causing failure of the structure progressively. The system as it collapses transfers the load into an alternate load path. The behaviour is linear static, non-linear static, linear dynamic, non-linear dynamic depending on the condition of initiation of failure and loading during the collapse mechanism.
The need for suitable approaches and guidelines for such analysis have become a necessity. The U.S. General Services Administration (GSA) ${ }^{1}$ and Department of Defence guidelines by United Facilities Criteria (UFC) ${ }^{2}$ New York, provide detailed stepwise procedure regarding methodologies for design to resist the progressive collapse of structure.

A simplified model for multiple floor system for progressive collapse assessment due to sudden loss of column considering about three floors above the lost column has been developed ${ }^{3}$. The analysis considers the nonlinear static response of the damaged structure under grav-

*Author for correspondence 
ity load, simplified dynamic assessment to establish the dynamic response under gravity load and Ductility of the connections.

An integrated software 'Opensees" have been developed ${ }^{4}$ which carries out the progressive collapse analysis automatically identifying the critical members and remodelling the structure. It conducts the iterative procedure automatically considering plastic hinges before producing the final results.

Reinforced concrete frames with masonry infill are a popular structural system. The masonry infills are generally not considered as structural members or restrains for design purposes. But the infill wall imparts sufficient rigidity and caries the redistributed loads from primary members and help in reducing progressive collapse.

Masonry infills are modelled in various forms. Under gravity loads the loading is transfer as diagonal compression and tension in two perpendicular directions in the infill walls and hence there is a tendency to model the infill as struts. However, the shell elements will project a more realistic behaviour. In addition, the effect of opening which is a practical phenomenon cannot be accounted if struts are used in the model.

A case study of the response of a six storeyed RC infilled frame of a building "Hotel San Diego, on removal of 2 exterior adjacent columns has been made ${ }^{5}$. The results of the FEM models where compared experimentally. The exterior walls were also modelled using strut and shell elements. It was concluded that the infilled walls offered support and constraints to the beam and act as mechanism for redistribution of loads. Shell elements are used in modelling of masonry infills in other researches ${ }^{6}$.

However, the openings in the wall were not accounted for.

An element which an articulated quadrilateral with rigid edges connected by four hinges and 2 diagonal nonlinear springs perpendicular and parallel to the panel sides is developed ${ }^{7}$ and used for masonry infill. The sides of the quadrilateral can interact with the elements by the nonlinear springs. The interface is also modelled by nonlinear springs.

Using the above element, the localised behaviour may be expressed more accurately. In progressive collapse analysis assessment of the global behaviour of the structure is required. The analysis will become cumbersome when such elements are used for finer discretization of panels.
Since masonry infills impart certain support to redistribution of load during loss of a member, it is necessary to study effect of infills in progressive collapse of RC frames. On the more under realistic conditions the presence of openings for utility in the masonry infill has not been considered in most of the analysis. Hence focus is done in this study the study the effect of openings also. The behaviour of RC structure under progressive collapse involves both material and structural non linearity. Stress strain curves for different grades of concrete and steel are available in standards and are built in most of the FEM software but specific standards are not available for stress strain curves for masonry as the properties depend on varied parameters.

A research ${ }^{8}$ has been conducted on uniaxial compressive stress strain model for clay brick masonry for three grades of mortar. A numerical model was developed and a simplified tri linear stress strain response was also idealized and presented.

In the absence of more accurate data this relationship is a handy tool for analysing masonry structures in the non-linear range.

Though the actual behaviour in progressive collapse is non-linear dynamic, due to its complexity most analysis and design methodologies advocate a linear static analysis with an enhanced load factor.

It is proposed to study the behaviour of 5 storey of Reinforced Concrete (RC) frames under progressive collapse on removal of critical column. The study will include a comparison between a bare frame and a frame with masonry infill wall to assess its effect on the frame to resist the progressive collapse. The study is extended to consider the effect of openings in the masonry infills.

The scope of the study is limited to a linear static analysis with load conditions as per GSA. This present research will be carried out on a $2 \mathrm{D}$ frame under gravity loads using finite element analysis software SAP 2000 version 16.

\section{Generation of Analytical Model}

\subsection{Structural Model}

Three different of models such as model 1- Bare frames, model 2- Infilled frames and model 3- Infilled frames with openings as shown in Figure 1 are studied. The beams 


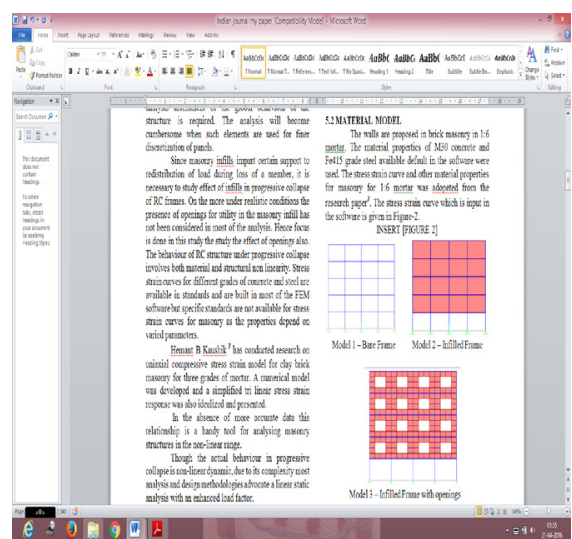

Figure 1. Structural models.

Table 1. Structural model details

\begin{tabular}{|l|l|l|l|l|}
\hline Models & $\begin{array}{l}\text { No. of } \\
\text { joints }\end{array}$ & $\begin{array}{l}\text { No. of } \\
\text { frame } \\
\text { element }\end{array}$ & $\begin{array}{l}\text { No. of } \\
\text { wall } \\
\text { elements }\end{array}$ & Load case \\
\hline 1 & 30 & 45 & - & $1.2 \mathrm{DL}+0.5 \mathrm{LL}$ \\
\hline 2 & 30 & 45 & 16 & $1.2 \mathrm{DL}+0.5 \mathrm{LL}$ \\
\hline 3 & 278 & 165 & 192 & $1.2 \mathrm{DL}+0.5 \mathrm{LL}$ \\
\hline
\end{tabular}

and columns are modelled as straight frame elements and masonry infill walls are modelled as shell element. The bases are fixed. The details of the structural models are tabulated in Table 1.

The beams and columns are proposed in RCC of M30 concrete and Fe415 grade steel. The beam and column size are $200 \times 400 \mathrm{~mm}$ and $450 \times 450 \mathrm{~mm}$ respectively. The reinforcement was designed manually based on the preliminary analysis for the above dimensions. The reinforcement detailing for beams are $2 \# 20 \mathrm{mmf}$ provided at the bottom and $2 \# 16 \mathrm{f}$ at the top. Stirrups of $10 \mathrm{mmf}$ provided. For columns $4 \# 20 \mathrm{mmf}$ are equally distributed on all 4 sides.

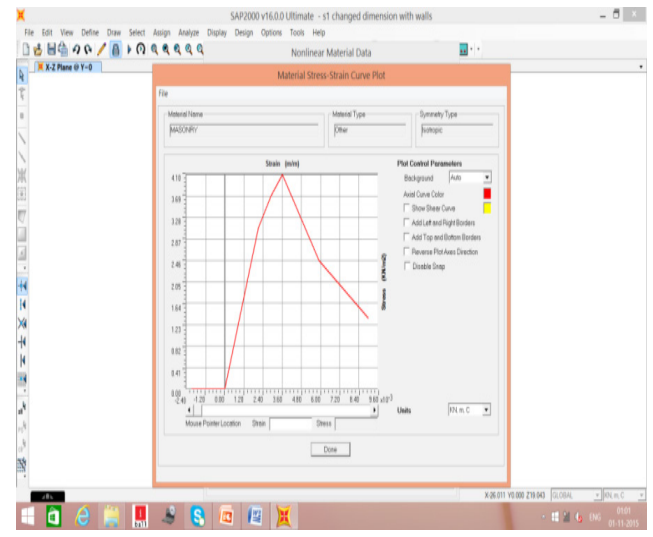

Figure 2. Stress strain curve for masonry.

\subsection{Material Model}

The walls are proposed in brick masonry in 1:6 mortar. The material properties of M30 concrete and Fe 415 grade steel available default in the software were used. The stress strain curve and other material properties for masonry for 1:6 mortar was adopted from the research paper. The stress strain curve which is input in the software is given in Figure 2.

\subsection{Applied Load Procedure}

As per IS 875 part 1\&2 1987 for dead load and live load for a residential building has been adopted in this analysis. For a Bare frame dead load consist of its own selfweight calculated by software. The other part of dead load is the slab load and wall load manually calculated and applied on the beams as a UDL. Live load of $4 \mathrm{kN} / \mathrm{m}$ is applied to the beams as a UDL at each floor. For an infill frame the same loadings were adopted except that the wall loads were calculated as part of the dead load by the software.

\subsection{Column Removal Scenario}

In this present study the middle column was removed for the various models. A middle column removal for bare frame is shown in Figure 3. It was done to observe the redistribution of moments, axial force, shear force in a structure. The results for bare Frame, infilled Frame, infilled Frame with openings with and without column removal were compared.

\section{Results and Discussion}

Linear static analysis of the three models was carried out under the action of dead load and live load and corre-

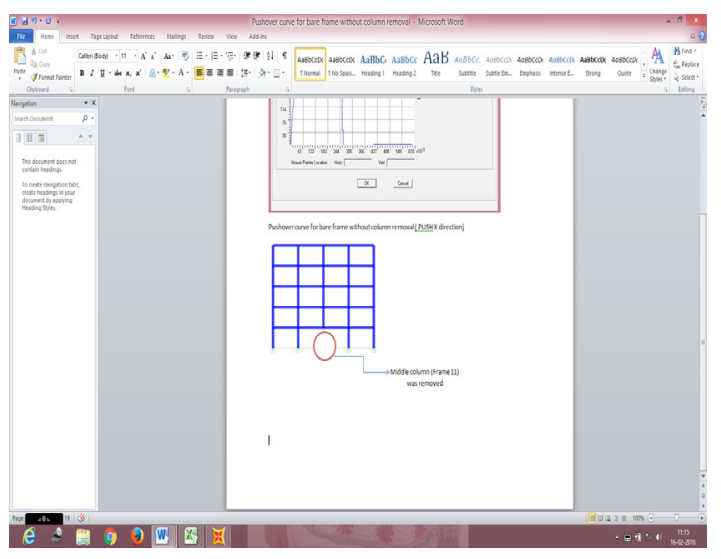

Figure 3. Column removal for a bare frame. 
sponding maximum force resultants in columns and beam of the frame obtained for the load case 1.2DL + $0.5 \mathrm{LL}$ as per GSA guidelines are compared in this section. This analysis is also carried for the same models with middle column removed.

The Figure $4(\mathrm{a}, \mathrm{b}, \mathrm{c})$ shows a graphical comparison of maximum moment, axial force and shear force respectively for column element for the three models before and after column removal. The variation of maximum axial force, shear force and moment in the columns for the

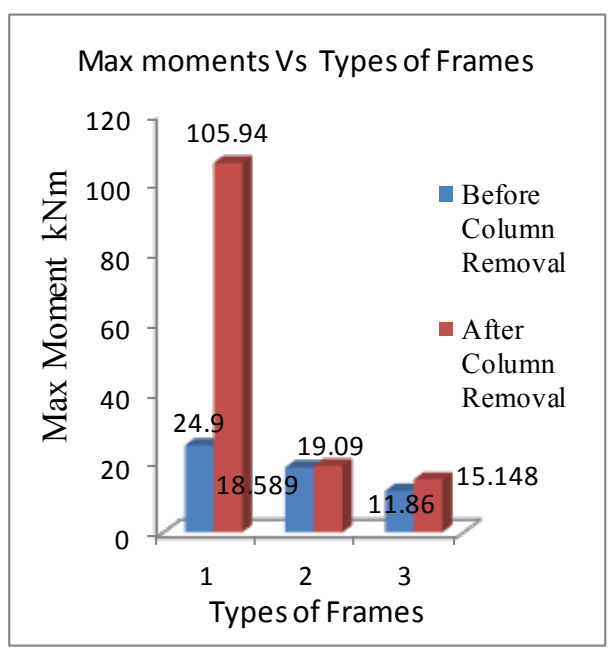

Figure 4. (a) Maximum moment on column for the three models before and after column removal.

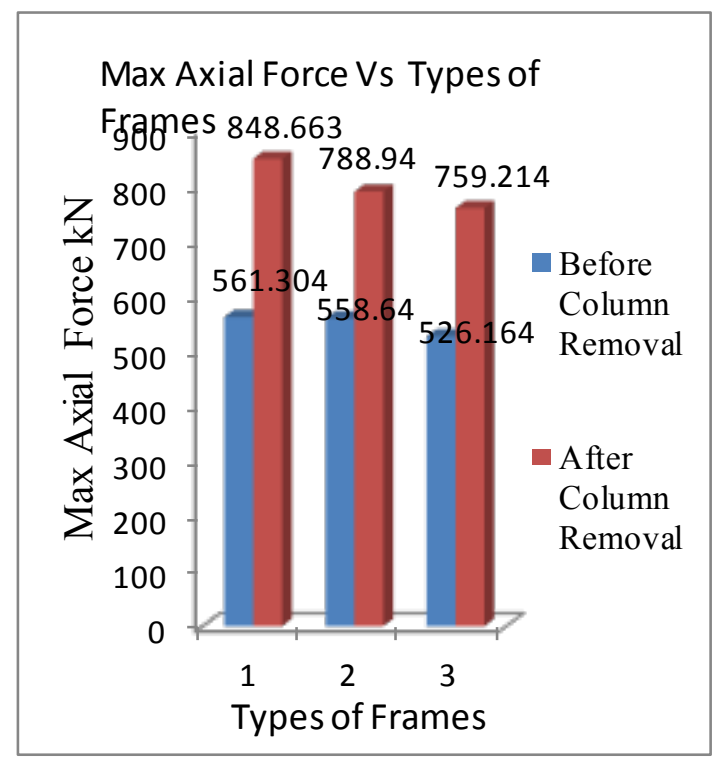

(b) Maximum Axial force on column for the three models before and after column removal.

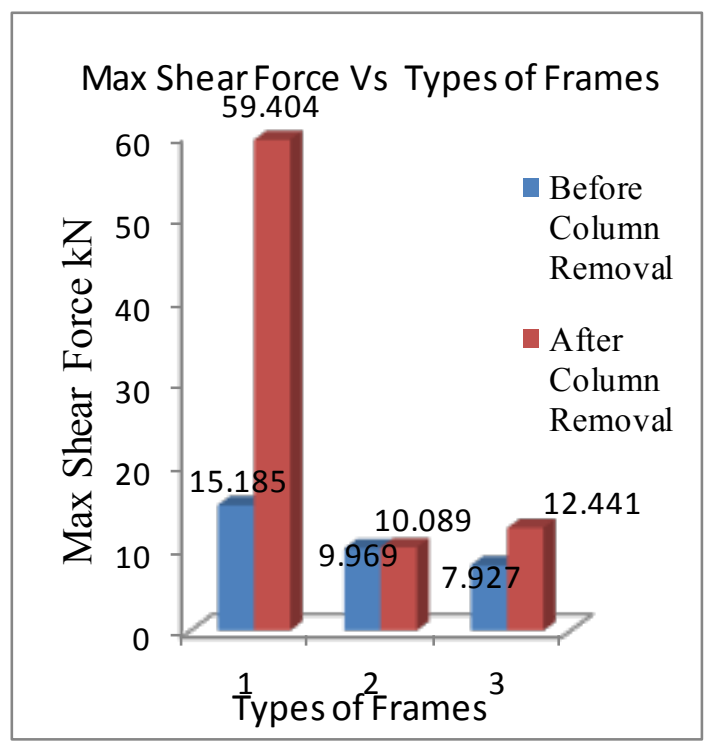

(c) Maximum shear force on column for the three models before and after column removal.

three types of models is minimum when considering the complete frame (without removal of column).

In the column removal scenario, the maximum axial force has increased considerably in the adjacent columns in comparison with the complete model but there is not much variation between the three models.

It appears that due to column removal the moment and shear force in the infilled frame does not vary much as compared to bare frame. But there is a considerable increase in the moment of the bare frame.

A graphical comparison of maximum moment, axial force and shear force for beam element for the three models before and after column removal is shown in Figure 5 $(a, b, c)$ respectively. Similar to the columns the variation of all the type of model is minimum when considering the complete frame. When the middle column is removed the maximum moment has increased considerably in the adjacent beams of the bare frame in comparison with the complete model, were as the increase in moment in the infilled frames and infill frame with the openings is comparatively less.

Similar behaviour is exhibited in the shear force with still lesser increase in the infilled frame and infilled frame with openings.

Generally, in beams axial force is very negligible. But due to column removal the axial force increase in all three models with the highest increase in the infilled frame with openings. 


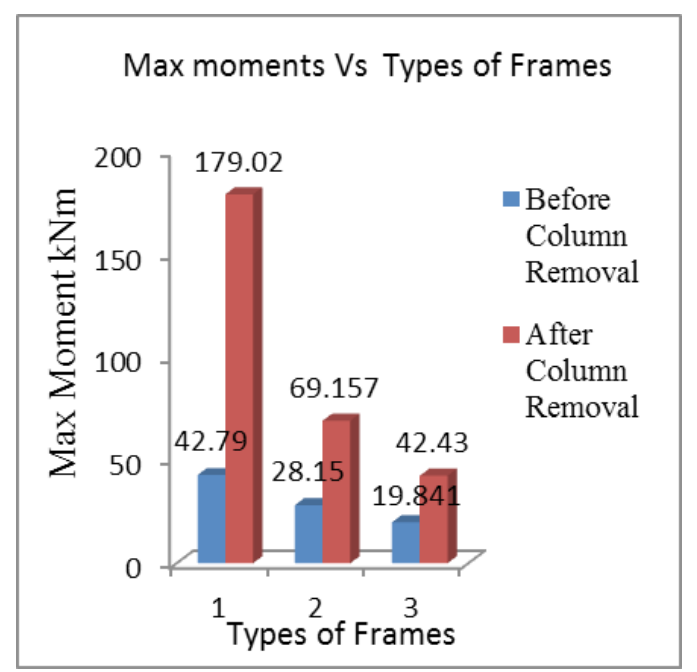

Figure 5. (a) Maximum moment on beam for the three models before and after column removal.

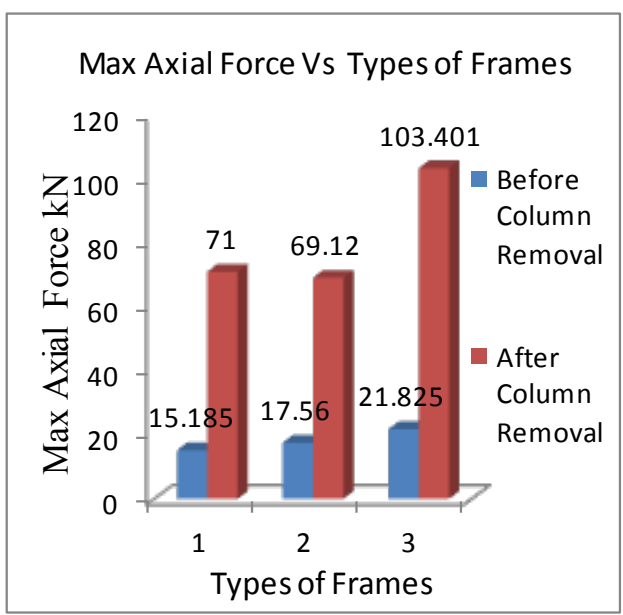

(b) Maximum axial force on beam for the three models before and after column removal.

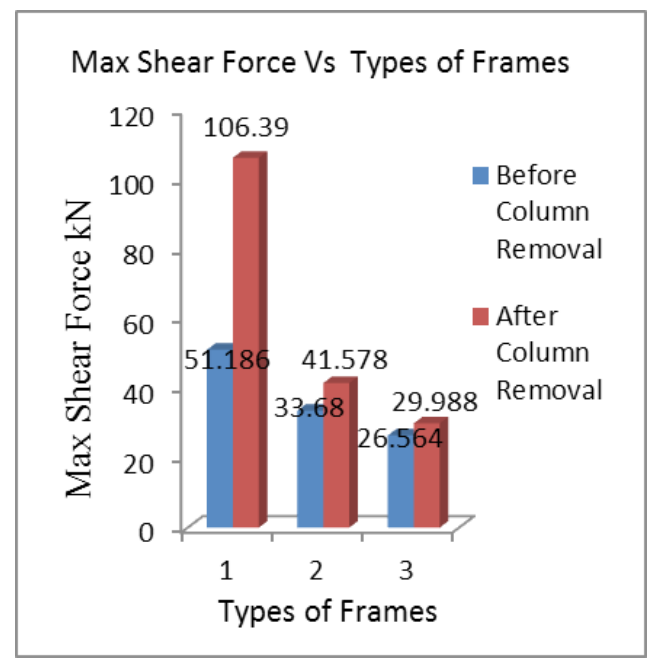

(c) Maximum shear force on beam for the three models before and after column removal.
The Figure $6(\mathrm{a} \& \mathrm{~b})$ shows the Bending moment and shear force diagram respectively after the column removal for a bare frame. It is observed that the moments and forces are higher in the beams and columns adjacent to the removed column it is due to redistribution of loads to the adjacent members.

The deflection for bare frame, infilled frames and infilled frames with openings is $1.1 \mathrm{~mm}, 0.76 \mathrm{~mm}$ and $0.8 \mathrm{~mm}$ respectively. After column removal the deflection for bare frame, infilled Frames and infilled frames with openings is $21.8 \mathrm{~mm}, 2.6 \mathrm{~mm}$ and $5 \mathrm{~mm}$ respectively. The deflection shape for an infilled frame with openings after column removal is shown in Figure 7.

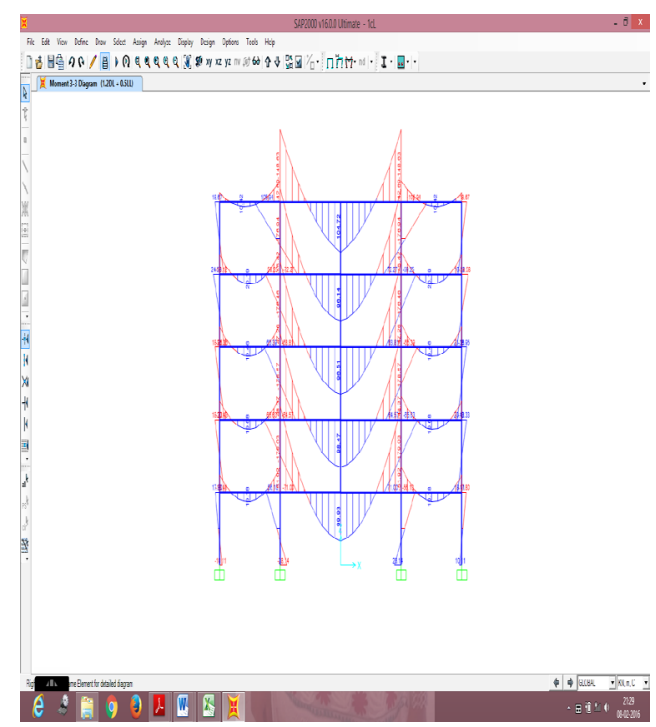

Figure 6. (a) Bending moment diagram for model 1 after removal of column.

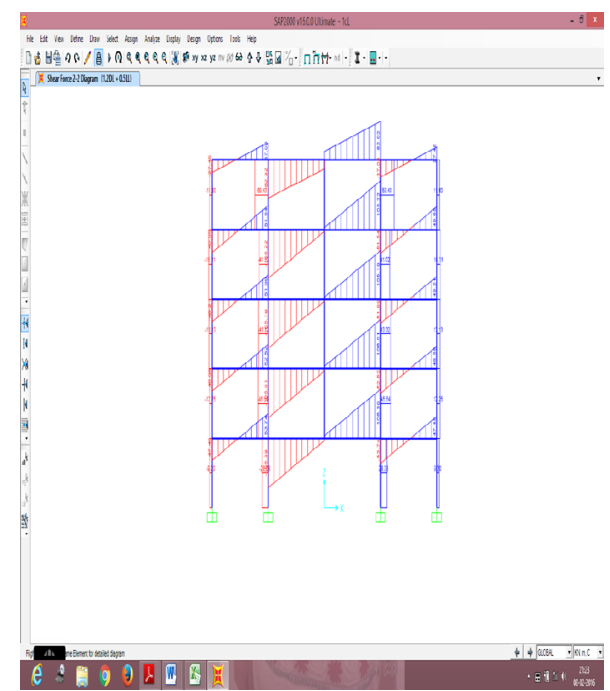

(b) Shear force diagram for model 1 after removal of column. 


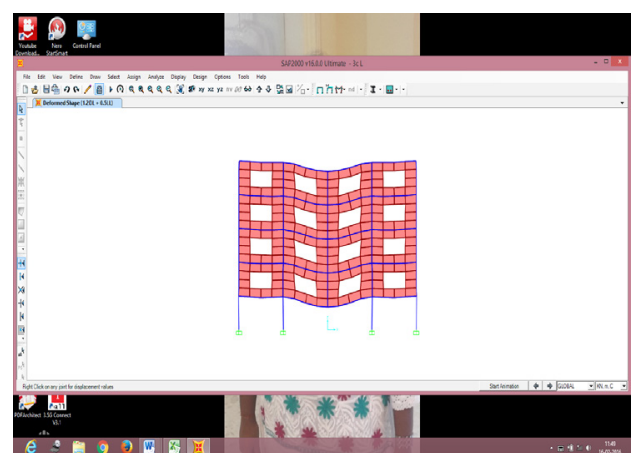

Figure 7. Deformed shape for Infilled Frames with openings.

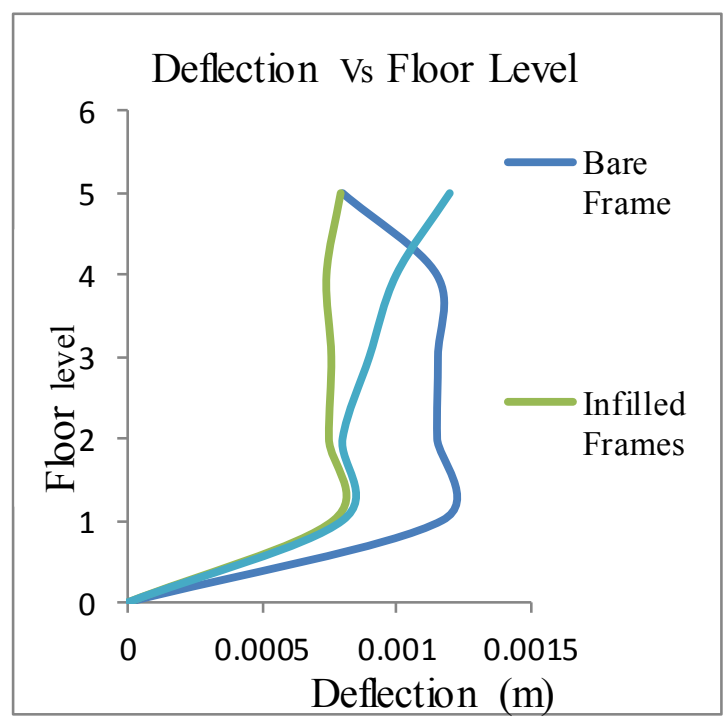

Figure 8. Deflection pattern for the three models before column removal.

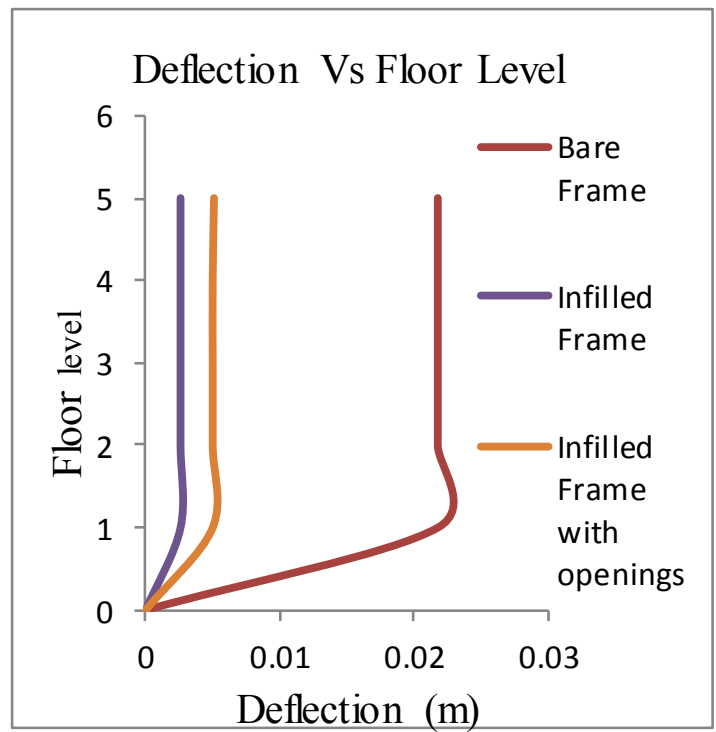

Figure 9. Deflection pattern for the three models after column removal.
Figures 8 \& 9 shows the deflected pattern for the three models before column removal and the deflection pattern for those models after column removal respectively. In the complete frame it is observed that the variation of maximum deflection between the three models is not considerable though the deflection in the bare frame is higher especially at the first floor level. On removal of column there is a drastic increase in deflection of the bare frame about 20times were as the variation in the deflection in the infill frames is lesser about 3 to 6 times.

Presence of infill walls definitely offer to act as a structural element for redistribution of moments and shear forces due to sudden loss of a primary column. However, presence of openings causes a mild decrease in redistribution.

It is preferable to have reduced the size of the openings so that the redistribution of loads to the infill walls will be more effective in delaying and mitigating progressive collapse.

\section{Conclusion}

1) Linear static analyses of the three models such as bare frame, infilled frame and infilled frames with openings were carried out under the action of dead load and live load.

2) Averages of $30 \%, 0.4$ to $13 \%$ and $34 \%$ decrease of moments, axial force and shear force in beams and columns were observed in infilled frame when compared with bare frame.

3) After column removal an average of $70 \%, 5 \%$ and $71 \%$ decrease in maximum moments, axial force and shear force for infilled frames compared with bare frames.

4) There is an average of $35 \%$ decrease in deflection for infilled frames when compared with bare frame and $17 \%$ increase for infilled frames with openings when compared to infilled frames without openings.

5) After column removal there is average of $88 \%$ decrease in deflection for infilled frames when compared with bare frame and average of $48 \%$ increase in deflection for infilled frames with openings when compared to infilled frames without openings.

6) It was observed that maximum moment, shear force, axial force and deflection is reduced due to the presence of the infilled walls.

7) From the deflection curves it is observed that the extent of openings bears an impact on the deflection of the structure. 
8) Presence of infill walls definitely offer to act as a structural element for redistribution of moments and shear forces due to sudden loss of a primary column. However, presence of openings causes a mild decrease in redistribution.

9) It is preferable to have reduced the size of the openings so that the redistribution of loads to the infill walls will be more effective in delaying and mitigating progressive collapse.

\section{Acknowledgement}

The author acknowledges the co-authors for their valuable guidance and involvement in the project. The special acknowledgement is due to the head department of civil engineering and SRM University for enabling to carry out this project.

\section{References}

1. U.S. General Services administration (GSA). Progressive collapse analysis and design guidelines for new federal office buildings and major modernization projects. Washington, DC; 2003.
2. U.S. Department of Defense. Design of building to resist progressive collapse UFC 4-023-03. Washington, DC; 2013 Jun.

3. Izzuddin BA, Vlassis AG, Elghazouli AY, Nethercot DA. Progressive collapse of multi-storey building due to sudden column loss- Part I: Simplified assessment framework. Engineering Structures. 2008 May; 30(5):1308-18.

4. Kim H-S, Kim J, An D-W. Development of integrated system for progressive collapse analysis of building structures considering dynamic effects. Advances in Engineering Software. 2009 Jan; 40(1):1-8.

5. Sasani M. Response of a reinforcement concrete infilledframe structure to removal of two adjacent columns. Engineering Structures. 2008 Sep; 30(9):2478-91.

6. Motwani P, Rajendhiran, Santhi AS. Simulation of brick infill and effect of openings on rc frames using ANSYS. Indian Journal of Science and Technology. 2015 Jan; 8(S2):29-35. DOI: 10.17485/ijst/2015/v8iS2/57798.

7. Calio I, Panto B. A macro-element modeling approach of infilled frame structures. Computers and Structures. 2014 Sep; 143:91-107.

8. Uniaxial compressive stress - strain model for clay brick masonry [Internet]. [Cited 2015 Oct 10]. Available from: http://www.iitk.ac.in/nicee/RP/2007_CS-Masonry_ Current_Science.pdf. 